BMJ Open Sport \& Exercise Medicine

\section{High prevalence of self-reported injuries and illnesses in talented female athletes}

To cite: Richardson A. Clarsen B., Verhagen E.A.L. $M$, et al. High prevalence of self-reported injuries and illnesses in talented female athletes. BMJ Open Sport Exerc Med 2017;3: 0000199. doi:10.1136/bmjsem-2016000199

Accepted 31 January 2017

\section{CrossMark}

\author{
${ }^{1}$ Faculty of Sports and \\ Nutrition, Amsterdam \\ University of Applied \\ Sciences, Amsterdam, The \\ Netherlands \\ ${ }^{2}$ Norwegian School of Sports \\ Sciences, Oslo Sports \\ Trauma Research Center, \\ Oslo, Norway \\ ${ }^{3}$ Department of Public and \\ Occupational Health, EMGO, \\ VU Medisch Centrum School \\ of Medical Sciences, \\ Amsterdam, The Netherlands \\ ${ }^{4}$ Codarts University of the \\ Arts, Rotterdam, The \\ Netherlands
}

Correspondence to A. Richardson, Faculty of Sports andNutrition, Amsterdam University of Applied Sciences, Amsterdam,The Netherlands; a.richardson@hva.nl

\section{ABSTRACT}

Background A thorough knowledge of the epidemiology and severity of injuries and illness in youth female elite sports is lacking due to the methodological challenges involved in recording them. In this study, the prevalence and incidence of injuries and illness are assessed among youth female elite athletes. Instead of solely focusing on time-loss injuries, our study included all substantial and nonsubstantial health problems (ie, injuries, mental problems and illnesses).

Methods Sixty young elite Dutch female athletes (age: 16.6 years (SD: 2.3), weight: $58.3 \mathrm{~kg}$ (SD: 15.1), height: $154.1 \mathrm{~cm}$ (SD: 44.2)) participating in soccer $(n=23)$, basketball $(n=22)$ and gymnastic $(n=15)$ talent development programmes were prospectively followed during one season (September 2014 to April 2015). To collect health problem data, all athletes completed the Oslo Sports Trauma Research Center Questionnaire on Health Problems every other week. Main outcome measures were average prevalence of injury and incidence density of injury.

Results At any given time, $47.9 \%$ of the athletes reported an injury ( $95 \% \mathrm{Cl} 43.6 \%$ to $52.6 \%)$ and $9.1 \%$ reported an illness $(95 \% \mathrm{Cl} 5.1$ to 19.0$)$. The average injury incidence density was 8.6 per 1000 hours of athlete exposure. The average number of self-reported injuries per athlete per season was significantly higher in soccer athletes $(4.3 \pm 2.7)$ than in basketball athletes $(2.6 \pm 2.0)(\mathrm{p}=0.03)$ and not significantly higher than in the gymnastic squad. The knee and the ankle were two of the most common injury locations for all squads. Knee injuries in basketball and soccer and heel injuries in the gymnastic squad had the highest impact on sports participation.

Conclusion High prevalence of self-reported injuries among talented female athletes suggests that future efforts towards their prevention are warranted.

\section{INTRODUCTION}

Overuse injuries, defined as injuries without a specific, identifiable event responsible for onset, may be a substantial problem in sports. ${ }^{1}$ Young athletes involved in elite talent development programmes are thought to have a particularly high risk of both overuse ${ }^{23}$ and acute injuries. ${ }^{4}$ In this group, high training volumes and overscheduling have been suggested to represent risk factors for overuse injury. ${ }^{5-7}$

\section{What are the new findings?}

This paper reports an injury incidence of 8.6 per 1000 hours of athlete exposure, an injury prevalence of $48 \%$, using a new injury recording method.

- The new injury recording method captures a complete picture of the burden of health complaints in young female elite athletes.

- The knee and the ankle were two of the three most common injury locations for all squads.

A thorough knowledge of the epidemiology of overuse injuries in youth sports is needed to target injury risk factors, and thereby prevent injury-related talent development stagnation and increase the return on investment in elite youth sports programmes. ${ }^{8}$ Baxter-Jones et al studied 64 elite young soccer and 119 elite young gymnast athletes and found a prevalence of overuse injuries of 15\% for soccer and 33\% for gymnasts. ${ }^{9}$ Yang et al found an overuse injury incidence of 2.0 per 1000 hours of athlete exposure among National Collegiate Athletic Association Division I basketball athletes. ${ }^{10}$ Although these studies indicate that overuse injuries in young athletes are common, they may underestimate the full extent of the problem. This is because most studies define injury as time loss from participation, whereas many athletes with overuse injuries continue to participate despite pain and reduced performance. ${ }^{11}$ When time loss definitions are used, about $90 \%$ of overuse injuries appear to be missed.

Clarsen $e t a l^{1}$ proposed a new surveillance method designed to address the methodological challenges involved in overuse injury registration, ${ }^{1}$ which was later adapted to record all types of health problems, including overuse injuries, acute injuries and illnesses. ${ }^{12}$ Using this method, athletes periodically report injury and illness symptoms and consequences using an electronic questionnaire. In comparison with standard methods of injury registration, this 
approach may provide greater information on true consequences of injury over time. ${ }^{1}{ }^{113}$ Although some athletic groups have been investigated using this new method, little is known about young talented female athletes, who are suggested to be a high-risk population. ${ }^{6}$ The aim of this study was to use this new method and gain more insight into the injuries and illnesses of young elite female athletes by recording injury and illness prospectively throughout a full season.

\section{MATERIALS AND METHODS}

\section{Subjects}

We invited all athletes $(\mathrm{n}=60$, mean age: $16.6, \mathrm{SD}=2.3$ years) involved in the soccer $(n=23)$, basketball $(n=22)$ and gymnastics $(n=15)$ squads of the Dutch national high-performance programme of the Centre for Top Sport and Education (CTO) Amsterdam, the Netherlands. To qualify for the programme, athletes must be nominated by their national federations and be competing at the national or international level in their sport. About 180 athletes in eight different sports are currently supported by CTO Amsterdam. The teams included in the study were a convenience sample, and all athletes and their parents were informed about the procedure and provided written informed consent. The study was approved by the Medical Ethics Committee of the Academic Medical Centre Amsterdam.

\section{Procedures}

During the preseason period (August 2014), the baseline characteristics were recorded by the medical staff of the CTO Amsterdam, including age, height and body weight. All athletes were prospectively followed during the entire 2014/2015 competitive season. The season runs from August 18 until April 26 for the soccer team (36 weeks) and from September 28 until April 26 (30 weeks) for the basketball and gymnastic teams. Every other week, all athletes were asked to complete questionnaires by using a web-based system (Monitoring Athletes, Trainers, Coaches and Health (MATCH) professionals). MATCH is developed by the Amsterdam University of Applied Sciences and used to monitor stress and recovery. This system consists of different questionnaires, including a Dutch translation of the Oslo Sports Trauma Research Center Questionnaire on Health Problems. ${ }^{12}$ This version was a forward-backwards translation from the original Norwegian version. ${ }^{7}$ Every fortnight on Sunday, athletes automatically received a link to the questionnaire by e-mail. If the athlete did not respond to the questionnaire within 3 days, a reminder by e-mail was sent. After 5 days of non-response, the coach was notified by the research team about uncompleted questionnaires. Subsequently, the coach asked the athletes personally to complete the questionnaire.

\section{IIIness and injury registration}

The questionnaire consisted of four key questions on the consequences of health problems on sport participation, training volume and sport performance, as well as the degree to which the athlete perceived symptoms. Each item is scored with a 4-point or 5-point scale, ranging from 0 (no problem, no reduction, no effect and no symptoms, respectively) to 25 (cannot participate at all or severe symptoms). The severity of a health problem was calculated on a scale of $0-100$ by summing the score of the four key questions, according to the method proposed by Clarsen et al. ${ }^{1}$ If the severity score was 0 , the questionnaire was finished for that 2-week period. However, if the severity score was higher than 0 , a health problem was registered, and if the athlete selected option 2 or 3 in either key question 2 or 3 , a substantial health problem was registered. ${ }^{12}$ Next, the athlete was asked whether she was referring to an injury or an illness. In case of an illness, no further information about the illness was registered. In case of an injury, the athlete was automatically directed to an injury registration form based on an international consensus statement on injury surveillance methodology for football ${ }^{14}$ to collect further details (eg, location, history and acute or overuse onset). At the end of this injury form, the athlete was asked if the injury was mentioned in the questionnaire of the previous biweekly period. If the athlete stated that the injury was previously mentioned, the severity score was added to the severity score of the previously mentioned injury to calculate the cumulative severity score for each case. Only one injury or illness could be registered. Finally, the athlete reported her training and match exposure minutes over the last 2 weeks.

\section{Statistical analysis}

All statistical procedures were performed using SPSS V.22. Baseline characteristics, measured as continuous variables, were expressed as mean and SD. Body mass index was calculated from athletes' baseline height and weight. The prevalence of all health problems (eg, illness, overuse injuries and acute injuries) was calculated for each biweekly period by dividing the number of reported problems by the number of respondents for that specific period. The prevalence of substantial problems (ie, a moderate or major reduction in sport activity and/or performance) was calculated separately. ${ }^{12}$ Injury incidence density (IID) was calculated as the number of new injuries per 1000 hours of sport participation. Injuries that were present at the start of the study were not taken into account. A Poisson model was used to obtain 95\% CI around the IID.

To calculate differences in injury characteristics between sports, independent samples t-tests were applied for the normally distributed continuous parameter (eg, reported injuries per athlete). $\mathrm{p}$ Values were two-tailed, and significance level was set at $\mathrm{p}<0.05$. To calculate the relative impact of injuries between the various sporting groups, a 
Table 1 Baseline characteristics shown as mean $( \pm \mathrm{SD})$

\begin{tabular}{lcccc}
\hline & Overall & Soccer & Basketball & Gymnastics \\
\hline $\mathrm{N}$ & 60 & 23 & 22 & 15 \\
Age, years & $16.6(2.3)$ & $17.2(1.2)$ & $17.7(1.2)$ & $14.0(2.8)$ \\
Weight, kg & $58.3(15.1)$ & $60.1(7.0)$ & $70.6(9.6)$ & $40.1(12.1)$ \\
Height, cm & $154.1(44.2)$ & $167.1(7.6)$ & $180.3(7.4)$ & $147.0(10.5)$ \\
Body mass index & $20.4(2.7)$ & $21.4(2.1)$ & $21.8(2.0)$ & $18.7(2.83)$ \\
Training exposure (hours) & $324(184)$ & $209(193)$ & $325(107)$ & $497(115)$ \\
Match exposure (hours) & $42(36)$ & $25(13)$ & $70(42)$ & $25(25)$ \\
\hline
\end{tabular}

cumulative severity score was calculated for each anatomical area for each sporting group by summing athletes' severity score over the total season, adjusted for differing group sizes and response rate. ${ }^{15}$ An assessment of scores of the relative impact of injuries was used to compare each anatomical area within and between sports.

\section{RESULTS}

\section{Response and baseline characteristics}

Fifty-nine of the 60 athletes enrolled in the study completed the entire follow-up period. The baseline characteristics of these athletes are shown in table 1 . One athlete dropped out the talent development programme during the season. In total, 970 questionnaires were sent to the athletes and 919 were completed, resulting in a response rate of $95 \%$.

\section{Prevalence of health problems}

During the season, a health problem was reported in 556 of the $919(60.5 \%)$ questionnaires. Of these, 440 were caused by an injury $(79.1 \%), 84$ by an illness $(15.1 \%)$ and 32 were unclassified (5.8\%). Of all reported health problems, a total of $282(30.7 \%)$ were classified as substantial. A majority of the substantial health problems were injury-related $(\mathrm{n}=232,82.3 \%)$. As shown in table 2, the average biweekly prevalence of substantial injury problems in the gymnastic squad is significantly lower than in both the soccer and basketball squads.

There was no significant difference on the prevalence of injuries between the biweekly periods. Figure 1 shows that there may be a trend indicating that the injury prevalence was higher at the start of the season and during the winter break (weeks 17-19).

\section{Characteristics of health problems}

Of all 556 reported health problems, 308 were unique (eg, not mentioned in the previous questionnaire). Of these, 192 were classified as an injury (62.3\%), 84 as illness $(27.3 \%)$ and 32 were unclassified health problems $(10.4 \%)$.

\section{IIInesses}

A total of 84 illnesses were reported by 44 athletes (27\% of all health problems), which equates to an

Table 2 Average biweekly prevalence of all health problems and of substantial problems, prevalence given as the biweekly per cent of injured players in the entire population $(95 \% \mathrm{Cl})$

\begin{tabular}{|c|c|c|c|c|}
\hline & Overall & Soccer & Basketball & Gymnastics \\
\hline All health problems & 60.5 (55.7 to 65.7$)$ & 61.1 (53.9 to 69.2) & 59.7 (51.6 to 69.2) & 60.5 (50.9 to 71.8$)$ \\
\hline Injury & 47.9 (43.6 to 52.6) & $48.0(41.7$ to 55.3$)$ & 46.6 (39.5 to 55.1$)$ & 49.3 (40.1 to 59.6$)$ \\
\hline Acute & 35.7 (32.0 to 39.7$)$ & 37.9 (32.4 to 44.4$)$ & 34.9 (28.8 to 42.3$)$ & 32.6 (25.8 to 41.2$)$ \\
\hline Overuse & 12.2 (7.6 to 23.3$)$ & $10.1(7.4$ to 13.7$)$ & 11.7 (8.4 to 16.4$)$ & 16.7 (12.1 to 23.2$)$ \\
\hline Illness & 9.1 (5.1 to 19.0$)$ & 9.1 (6.6 to 12.6$)$ & 10.7 (7.6 to 15.1$)$ & 7.0 (4.2 to 11.6$)$ \\
\hline Unclassified & 3.5 (1.3 to 10.9$)$ & 3.9 (2.4 to 6.4$)$ & 2.3 (1.1 to 4.9$)$ & 4.2 (2.2 to 8.0$)$ \\
\hline Substantial health problems & 30.7 (23.45 to 47.6$)$ & 34.7 (29.4 to 41.0$)$ & 33.6 (27.6 to 40.8$)$ & 19.1 (14.0 to 25.9$)$ \\
\hline Injury & 25.2 (18.6 to 40.5$)$ & 28.3 (23.6 to 34.0$)$ & $27.9(22.5$ to 34.5$)$ & $15.8(11.3$ to 22.1$)$ \\
\hline Acute & 20.2 (14.2 to 34.0$)$ & 23.4 (19.1 to 28.6$)$ & 22.8 (18.0 to 28.9$)$ & $10.7(7.1$ to 16.1$)$ \\
\hline Overuse & $5.0(2.2$ to 13.1$)$ & 4.9 (3.2 to 7.6$)$ & 5.0 (3.0 to 8.3 ) & 5.1 (2.8 to 9.2$)$ \\
\hline Illness & 4.1 (1.7 to 11.8$)$ & 5.2 (3.4 to 7.9$)$ & 4.7 (2.8 to 7.9$)$ & 1.4 (0.5 to 4.3$)$ \\
\hline Unclassified & 1.3 (0.3 to 7.9$)$ & 1.2 (0.5 to 3.0$)$ & 1.0 (0.3 to 3.1$)$ & 1.9 (0.7 to 5.0$)$ \\
\hline
\end{tabular}


Figure 1 Biweekly prevalence of injuries during the 36-week followup period. Full line represents all reported injuries, whereas dotted line represents substantial injuries.
Overall

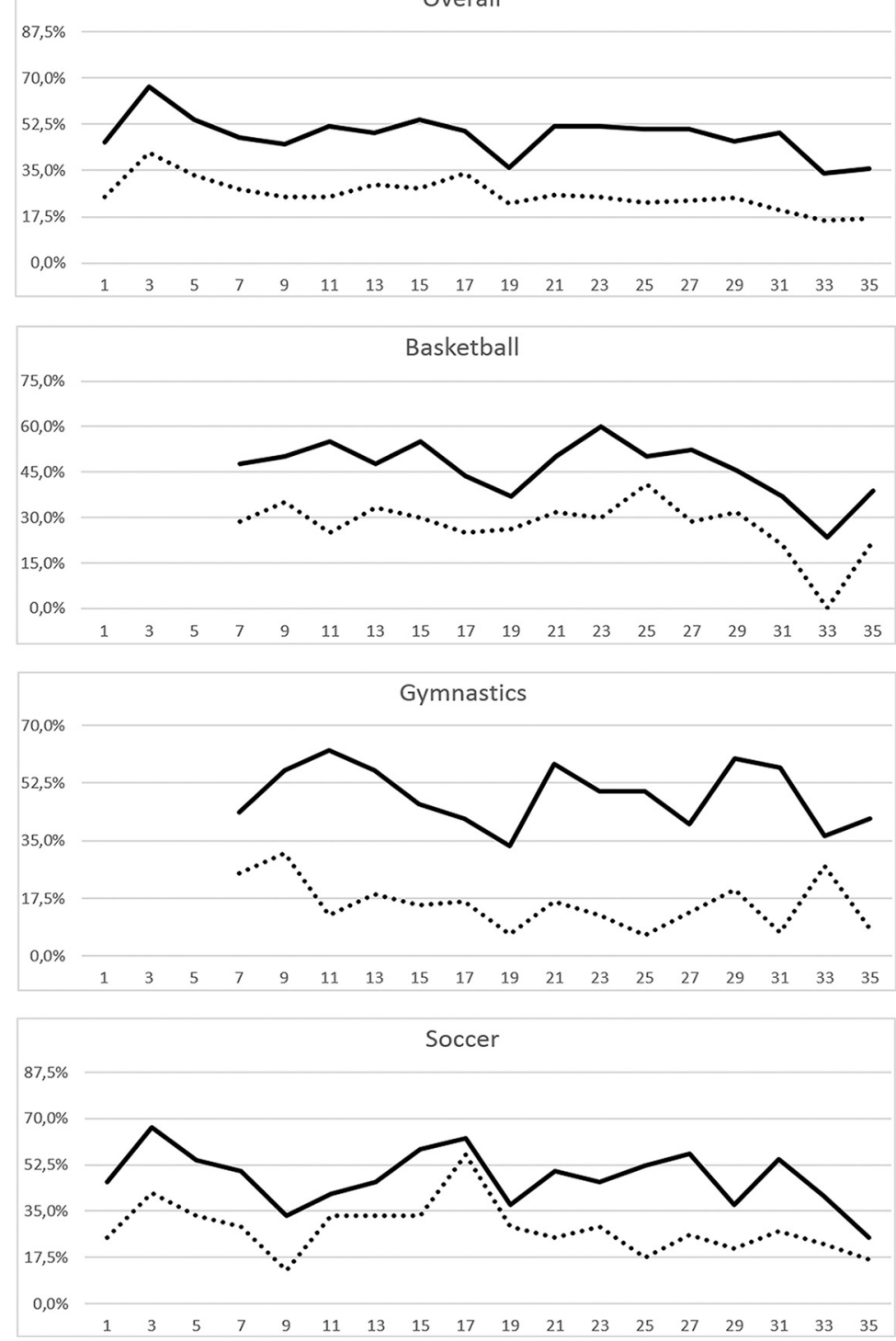

per 1000 hours (95\% CI 7.4 to 9.9). Injury incidence in the soccer squad (17.1 injuries per 1000 hours; 95\% CI 14.0 to 21.0) was significantly higher than in the basketball squad (6.3 injuries per 1000 hours; 95\% CI 4.9 to 8.2 ) and the gymnastic squad (5.2 injuries per 1000 hours; $95 \%$ CI 3.9 to 7.1 ) (table 4 ).

The most common acute injury locations were the ankle $(n=36 ; 18.8 \%)$, knee $(n=31 ; 16.1 \%)$ and the posterior upper leg $(n=24 ; 12.5 \%)$, whereas the most common overuse injury locations were the knee $(n=12$; $20.3 \%)$, posterior upper leg $(n=7 ; 11.9 \%)$, lower back $(\mathrm{n}=5 ; 8.5 \%)$ and the heel $(\mathrm{n}=5 ; 8.5 \%)$. Table 5 shows the most common injury locations for each sport.

\section{Relative impact of injuries}

Figure 3 shows the top 10 of the relative impact of injuries in each anatomical area for each sport, based on the adjusted cumulative severity score over the total season. As shown in the figure, heel injuries among gymnasts, knee injuries among basketball athletes and 
Table 3 Average, mean and range of the biweekly severity score of injuries per sport

\begin{tabular}{lllll}
\hline & N & Mean (SD) & Median & Range \\
\hline Soccer & 94 & $34.0(22.5)$ & 27.8 & $6.0-92.4$ \\
Basketball & 55 & $32.8(20.0)$ & 33.0 & $8.0-83.0$ \\
Gymnastics & 43 & $26.5(13.8)$ & 27.4 & $8.0-68.8$ \\
\hline
\end{tabular}

knee injuries among soccer athletes had the greatest impact on athletes' performance and participation.

\section{DISCUSSION}

The main finding of this study was that the average biweekly prevalence of health problems was $60.5 \%$ (95\% CI 55.7 to 65.7 ). Furthermore, injuries are the main problem, with an average biweekly prevalence of $47.9 \%$ (95\% CI 43.6 to 52.6). This is higher than the prevalence of injuries found in Norwegian Olympic and Paralympic adult athletes using similar data collection methods. ${ }^{12}$ This might be explained by several factors. First, the athletes in our study are adolescents. The musculoskeletal system of adolescents is not fully developed, which may increase the risk of injuries. ${ }^{16-18}$ This is underlined by the adolescent growth sportinduced alterations in limb length, body mass and moments of inertia, which may affect coordination and movement patterns. These physical alterations may play a role in the increased risk of injuries. ${ }^{17}$ 19-24 Second, our participants are all female. It is well documented that women are at higher injury risk compared with men for many injury types. ${ }^{25-28}$ Some studies attribute the increased injury rate to gender-based anatomical differences, such as joint laxity, bone structures and limb alignment. ${ }^{27}$ Other studies have suggested that female hormones are directly involved in female injury rates. ${ }^{29-31}$ Especially after the onset of maturation, differences in circadian sex hormones are attributable to imbalances in neuromuscular control, which may cause an increased injury risk in pubertal women. ${ }^{32-34}$

In the soccer squad, we found an incidence of 17.1 injuries per 1000 athletic exposure (95\% CI 14.0 to 21.0), which is significantly higher than the incidence found in the study of young elite female soccer players (6.4; $95 \%$ CI 5.9 to 6.9$){ }^{35}$ Furthermore, we found an incidence of 5.2 (95\% CI 3.9 to 7.1 ) injuries per 1000

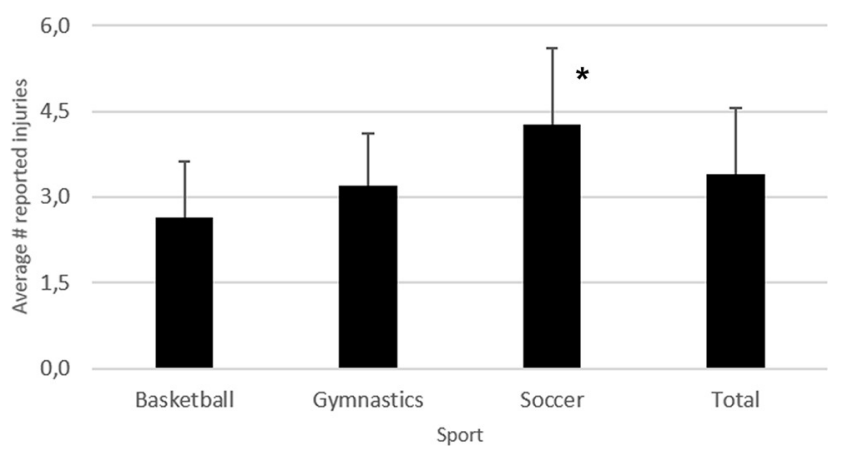

Figure 2 The average number of injuries reported per player. *Significantly different from the basketball squad $(p<$ $0.05 \%)$.

athletic exposure in the gymnastic squad, which is higher than the injury incidence of 2.9 found in the study of young elite female gymnasts. ${ }^{36}$ In the basketball squad, we found an injury incidence of 6.3 (95\% CI 4.9 to 8.2 ), which is significantly lower than the injury incidence of 13.9 (95\% CI 11.2 to 16.7 ) in the study of female basketball players in Flanders' national and regional competition. ${ }^{37}$ The differences in the injury incidence in the soccer and gymnastic squads can be explained by the use of different injury definitions. Both studies used the consensus statement for injury surveillance methods in football. ${ }^{14}$ Our results substantiate this suggestion. The differences in injury incidence may be even greater, as it is not clear whether the studies excluded injuries that were present at the start of the study. Clarsen et al showed that $44 \%$ of identified injuries in their study would have been excluded in incidence calculation for this reason. ${ }^{1}$ Furthermore, as suggested by Clarsen et al, the injury registration method used in our study can identify more than 10 times as many cases than this standard method. ${ }^{1}$ Apart from a possible overestimation of injury incidence, the lower injury incidence in the basketball squad may be explained by the different competing levels the subjects were involved in. There is some scientific evidence that athletes performing at international levels are at lower injury risk than athletes performing at the national level. ${ }^{38}{ }^{39}$ Internationals have more sports medicine and sports science and coaching resources working in a coordinated fashion, resulting in a better understanding of injury risks and injury prevention, which may result in a lower injury risk. Furthermore, the higher injury incidence found by Cumps et al is also a result of the injury

Table 4 Injury incidence density characteristics per sport, \% (95\% Cl)

\begin{tabular}{llclc}
\hline & \multicolumn{1}{c}{ Overall } & \multicolumn{1}{c}{ Soccer } & Basketball & Gymnastics \\
\hline All reported injuries & $8.6(7.4$ to 9.9$)$ & $17.1(14.0$ to 21.0$)$ & $6.3(4.9$ to 8.2$)$ & $5.2(3.9$ to 7.1$)$ \\
Acute injuries & $5.9(5.0$ to 7.0$)$ & $12.5(9.9$ to 15.9$)$ & $4.4(3.2$ to 6.0$)$ & $3.2(2.2$ to 4.6$)$ \\
Overuse injuries & $2.6(2.0$ to 3.4$)$ & $4.5(3.0$ to 6.7$)$ & $2.0(1.2$ to 3.2$)$ & $2.1(1.3$ to 3.3$)$ \\
\hline
\end{tabular}

All data are injury incidence per 1000 hours of athlete exposure, with $95 \% \mathrm{Cl}$ in parentheses. 
Table 5 Total number of injuries and acute injuries per location overall and per sport (\%)

\begin{tabular}{ccccc}
\hline & Overall & Soccer $^{*}$ & Basketball* & Gymnastics* $^{*}$ \\
\hline Groin & $10(5)^{5}$ & $6(6)$ & $2(4)$ & $2(5)$ \\
\hline Acute & $8(4)$ & $4(4)$ & $2(4)$ & $2(5)$ \\
\hline Thigh anterior & $24(13)$ & $19(20)$ & $4(7)$ & $1(2)$ \\
\hline Acute & $17(9)$ & $14(15)$ & $3(5)$ & $0(0)$ \\
\hline Knee & $31(16)$ & $14(15)$ & $11(20)$ & $6(14)$ \\
\hline Acute & $19(10)$ & $9(10)$ & $7(13)$ & $3(7)$ \\
\hline Ankle & $36(19)$ & $17(18)$ & $14(26)$ & $5(11)$ \\
\hline Acute & $32(16)$ & $15(16)$ & $14(26)$ & $3(7)$ \\
\hline Heel & $6(3)$ & $0(0)$ & $2(4)$ & $4(9)$ \\
\hline Acute & $1(0.5)$ & $0(0)$ & $1(2)$ & $6(14)$ \\
Foot and toes & $11(6)$ & $4(4)$ & $1(2)$ & $6(14)$ \\
\hline Acute & $10(5)$ & $4(4)$ & $0(0)$ & $43(100)$ \\
Total & $192(100)$ & $94(100)$ & $55(100)$ & $226(60)$ \\
\hline Acute & $133(69)$ & $69(73)$ & $38(69)$ & \\
\hline
\end{tabular}

*Percentages are shown as percentage of injury location within sport.

definition that was used, as it included serious, moderate and minor injuries. This definition is similar to the definition used in this study.

Although injury incidence differed from other studies, the majority of injury locations in our study were in agreement with other studies. The majority of injuries were located at the ankle and knee for all squads. Thigh injuries supplemented the top three injury list in the soccer and basketball squads, whereas it was the foot in the gymnastic squad. These results are similar to other studies on adult ${ }^{26} \quad 40-42$ and young ${ }^{35} 36$ female elite athletes. The relatively high average prevalence of heel injuries in gymnastics and knee injuries in soccer and basketball supports the fact that the foot (gymnastics) and the knee (soccer and basketball) are the most commonly affected areas. ${ }^{26} 35$
36 40-42 The relative average prevalence of heel injuries in the gymnastic squad was at least double of the prevalence of all injuries in the other squads. This indicates that gymnastic prevention programmes should focus on heel injuries. Soccer and basketball squads should focus on the prevention of knee problems, for example with the $11+$ injury prevention programme ${ }^{43}$ and the ankle prevention programme, freely available as an interactive app ('Strengthen Your Ankle' translated in Dutch as: 'Versterk je enkel'; available for iOS and Android). ${ }^{44}$

One major strength of this study is the response rate of the biweekly questionnaire of $95 \%$. There are several reasons that might explain the high response rate. For example, we used adequate guidance during the season to increase the involvement of athletes and
Figure 3 Top 10 of the relative impact of injuries shown as the adjusted cumulative severity score for each group (arbitrary units). BB, basketball; GN, gymnastics; SC, soccer.

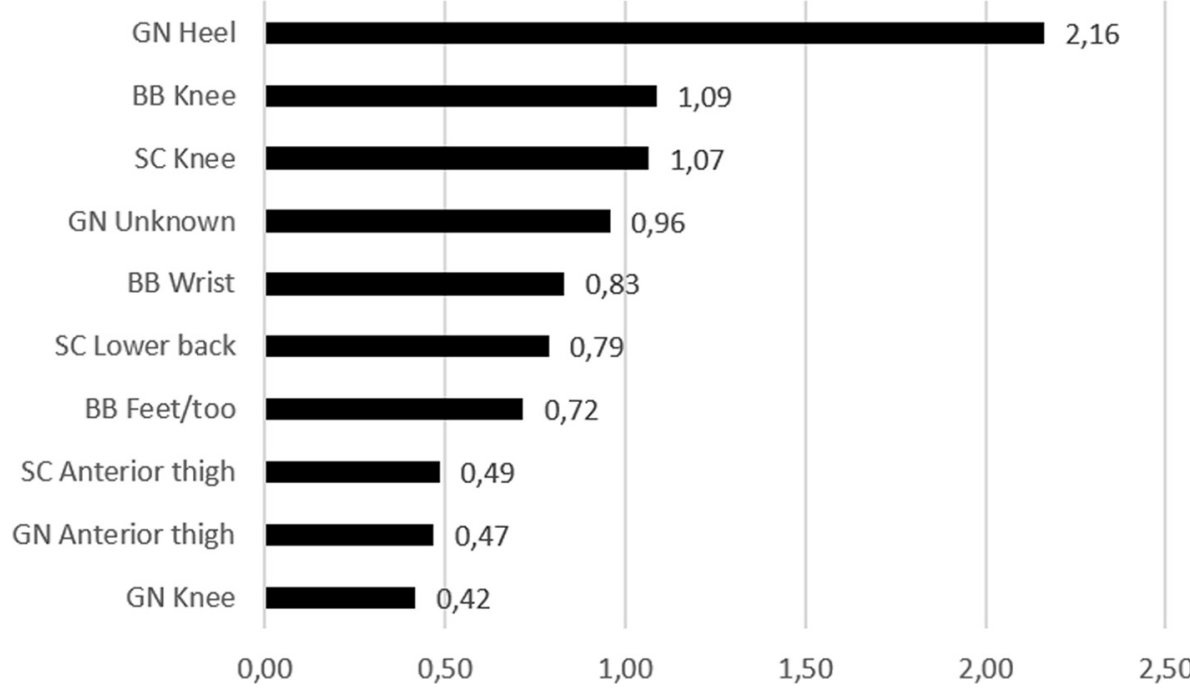


coaches. In addition, we used MATCH to give coaches visual feedback of the collected data to improve their commitment to this study. We recommend to use this approach when using similar registration methods.

A unique aspect of this study is that all participants were active in a professional sports talented programme for female athletes. A thorough investigation on the severity and magnitude of self-reported health problems in this group is missing. Although the sample size is relatively small, the presented data are accurately measured and can be seen as a thorough representation of the real life.

In this study, we used athlete-reported outcomes. This methodology exposes a potential limitation. Most talented athletes lack medical expertise. Therefore, we were unable to record specific diagnoses for the reported injuries and profound onset mechanisms. We recommend that future studies include a follow-up from the medical staff during the data collection period to gain more insight in the injury type and aetiology. As the focus of this study was to reveal the magnitude and severity of self-reported health problems, we chose to restrict athletes to report only injury locations. However, future studies may better target a specific injury prevention programme for common injuries, when specific medical data of injuries are available. ${ }^{45}$ Moreover, training and match exposure may be difficult to be defined by the athletes as time on the pitch may not equal exposure time. Future studies can include coaches in defining training and match exposure.

The second limitation is that athletes recorded a questionnaire every other week, instead of every week, as proposed by Clarsen et al. ${ }^{1}$ This may have led to a slight underestimation of health problems, as athletes may forget a health problem that occurred 2 weeks earlier. In addition, the used methodology implies that the problem's severity is constant between two recordings. It is, therefore, unclear at what specific day the severity of the health problem was the highest. However, due to this method, the athletes were not overloaded with questionnaires every week, leading to a very high compliance. Furthermore, we believe that athletes are able to provide reliable information about a health problem from prior to 2 weeks. Clarsen et al showed that the average prevalence and severity of health problems were not affected by the sampling frequency of up to a frequency of one sample every 4 weeks. ${ }^{1}$

Third, the injury definition is very broad. Therefore, some normal aches and pains being part of the sport (eg, delayed onset muscle soreness) may be recorded as an injury. To prevent overestimation of injury prevalence, substantial health problems (ie, reduction in activity and sports performance) were included in this study, which were also very high. Nevertheless, monitoring the severity of normal aches and pains over time may reveal worsening problems. Adequate preventive interventions targeting these problems may prevent athletes to cease participation in training and competition.

Moreover, the data in this study are based on single teams. These teams are not necessarily representative of all young elite female athletes in these sports. Nevertheless, the results in this study identify the extent and severity of the sports injury problem, which can be used to identify risk factors and reduce future risks of these particular injuries in general.

Finally, in this study, only basic data were collected, but as the focus of this study was injury, no attempt was made to record illness symptoms or classify illness types. Nevertheless, our data are sufficient to conclude that illness rates were low in these athletes (normal population estimates of 2-3 respiratory tract infections per year) and injuries represent the major burden.

Funding This work was supported by National Association of Applied Sciences SIA Grant Number 2013-15-12P.

Competing interests None declared.

Ethics approval The Medical Ethics Committee of the Academic Medical Centre (AMC) Amsterdam.

Provenance and peer review Not commissioned; externally peer reviewed

Open Access This is an Open Access article distributed in accordance with the Creative Commons Attribution Non Commercial (CC BY-NC 4.0) license, which permits others to distribute, remix, adapt, build upon this work noncommercially, and license their derivative works on different terms, provided the original work is properly cited and the use is non-commercial. See: http:// creativecommons.org/licenses/by-nc/4.0/

(c) Article author(s) (or their employer(s) unless otherwise stated in the text of the article) 2017. All rights reserved. No commercial use is permitted unless otherwise expressly granted.

\section{REFERENCES}

1. Clarsen B, Myklebust G, Bahr R. Development and validation of a new method for the registration of overuse injuries in sports injury epidemiology: the Oslo Sports Trauma Research Centre (OSTRC) overuse injury questionnaire. Br J Sports Med 2013;47:495-502.

2. DiFiori JP, Benjamin HJ, Brenner JS, et al. Overuse injuries and burnout in youth sports: a position statement from the American Medical Society for Sports Medicine. Br J Sports Med 2014;48:287-8.

3. Jayanthi NA, LaBella CR, Fischer D, et al. Sports-specialized intensive training and the risk of injury in young athletes: a clinica case-control study. Am J Sports Med 2015;43:794-801.

4. Maffulli N, Longo UG, Spiezia F, et al. Aetiology and prevention of injuries in elite young,athletes. Med Sport Sci 2011;56:187-200.

5. Visnes H, Aandahl HA, Bahr R. Jumper's knee paradox-jumping ability is a risk factor for developing jumper's knee: a 5-year prospective study. Br J Sports Med 2013;47:503-7.

6. Bahr R. Demise of the fittest: are we destroying our biggest talents? Br J Sports Med 2014;48:1265-7.

7. Pluim BM, Loeffen FG, Clarsen B, et al. A one-season prospective study of injuries and illness in elite junior tennis. Scand J Med Sci Sports 2016;26.

8. Arliani GG, Belangero PS, Runco JL, et al. The Brazilian Football Association (CBF) model for epidemiological studies on professional soccer player injuries. Clinics 2011;66:1707-12.

9. Baxter-Jones A, Maffulli N, Helms P. Low injury rates in elite athletes. Arch Dis Child 1993;68:130-2.

10. Yang J, Tibbetts AS, Covassin T, et al. Epidemiology of overuse and acute injuries among competitive collegiate athletes. J Athl Train 2012;47:198-204.

11. Bahr R. No injuries, but plenty of pain? on the methodology for recording overuse symptoms in sports. $\mathrm{Br} J$ Sports Med 2009;43:966-72. 
12. Clarsen B, Rønsen O, Myklebust G, et al. The Oslo Sports Trauma Research Center questionnaire on health problems: a new approach to prospective monitoring of illness and injury in elite athletes. $\mathrm{Br} \mathrm{J}$ Sports Med 2014;48:754-60.

13. Fredriksen $\mathrm{H}$, Clarsen $\mathrm{B}$. High prevalence of injuries in the norwegian national ballet. Br J Sports Med 2014;48:595.3-6.

14. Fuller CW, Ekstrand J, Junge A, et al. Consensus statement on injury definitions and data collection procedures in studies of football (soccer) injuries. Clin J Sport Med 2006;16:97-106.

15. Clarsen B, Bahr R, Heymans MW, et al. The prevalence and impact of overuse injuries in five Norwegian sports: application of a new surveillance method. Scand J Med Sci Sports 2015;25:323-30.

16. Bright RW, Burstein AH, Elmore SM. Epiphyseal-plate cartilage. A biomechanical and histological analysis of failure modes. $J$ Bone Joint Surg Am 1974;56:688-703.

17. Feeley BT, Agel J, LaPrade RF. When is it too early for single sport specialization? Am J Sports Med 2016;44.

18. Hawkins D, Metheny J. Overuse injuries in youth sports: biomechanical considerations. Med Sci Sports Exerc 2001;33:1701-7.

19. DiFiori JP, Puffer JC, Aish B, et al. Wrist pain in young gymnasts: frequency and effects upon training over 1 year. Clin J Sport Med 2002;12:348-53.

20. Duggleby T, Kumar S. Epidemiology of juvenile low back pain: a review. Disabil Rehabil 1997;19:505-12.

21. Keeley DW, Hackett T, Keirns M, et al. A biomechanical analysis of youth pitching mechanics. J Pediatr Orthop 2008;28:452-9.

22. Sabick MB, Kim YK, Torry MR, et al. Biomechanics of the shoulder in youth baseball pitchers: implications for the development of proximal humeral epiphysiolysis and humeral retrotorsion. Am J Sports Med 2005;33:1716-22.

23. Niemeyer $\mathrm{P}$, Weinberg $\mathrm{A}$, Schmitt $\mathrm{H}$, et al. Stress fractures in the juvenile skeletal system. Int J Sports Med 2006;27:242-9.

24. Flachsmann R, Broom ND, Hardy AE, et al. Why is the adolescent joint particularly susceptible to osteochondral shear fracture? Clin Orthop Relat Res 2000;381:212-21.

25. Arendt $E$, Dick R. Knee injury patterns among men and women in collegiate basketball and soccer. NCAA data and review of literature. Am J Sports Med 1995;23:694-701.

26. Deitch JR, Starkey C, Walters SL, et al. Injury risk in professional basketball players: a comparison of Women's National Basketball Association and National Basketball Association athletes. Am J Sports Med 2006;34:1077-83.

27. Hewett TE, Lindenfeld TN, Riccobene JV, et al. The effect of neuromuscular training on the incidence of knee injury in female athletes. A prospective study. Am J Sports Med 1999;27:699-706.

28. Soligard T, Myklebust G, Steffen K, et al. Comprehensive warm-up programme to prevent injuries in young female footballers: cluster randomised controlled trial. BMJ 2008;337:a2469.
29. Hewett TE, Stroupe AL, Nance TA, et al. Plyometric training in female athletes. Decreased impact forces and increased hamstring torques. Am J Sports Med 1996;24:765-73.

30. Hewett TE, Zazulak BT, Myer GD. Effects of the menstrual cycle on anterior cruciate ligament injury risk: a systematic review. $A m J$ Sports Med 2007;35:659-68.

31. Zelisko JA, Noble HB, Porter M. A comparison of men's and women's professional basketball injuries. Am J Sports Med 1982;10:297-9.

32. Zazulak BT, Paterno M, Myer GD, et al. The effects of the menstrual cycle on anterior knee laxity: a systematic review. Sports Med 2006;36:847-62.

33. Hewett TE, Myer GD, Ford KR. Decrease in neuromuscular control about the knee with maturation in female athletes. $J$ Bone Joint Surg Am 2004:86-A:1601-8.

34. Hewett TE. Neuromuscular and hormonal factors associated with knee injuries in female athletes. strategies for intervention. Sports Med 2000;29:313-27.

35. Le Gall F, Carling C, Reilly T. Injuries in young elite female soccer players: an 8-season prospective study. Am J Sports Med 2008;36:276-84.

36. Saluan P, Styron J, Ackley JF, et al. Injury types and incidence rates in precollegiate female gymnasts: a 21-Year experience at a single training facility. Orthop J Sports Med 2015;3:2325967115577596.

37. Cumps E, Verhagen E, Meeusen R. Prospective epidemiological study of basketball injuries during one competitive season: ankle sprains and overuse knee injuries. J Sports Sci Med 2007;6:204-11.

38. Keightley M, Reed N, Green S, et al. Age and competition level on injuries in female ice hockey. Int J Sports Med 2013;34:756-9.

39. Verrall G, Darcey A. Lower back injuries in rowing national level compared to international level rowers. Asian J Sports Med 2014;5:e24293.

40. Engström B, Johansson $\mathrm{C}$, Törnkvist $\mathrm{H}$. Soccer injuries among elite female players. Am J Sports Med 1991;19:372-5.

41. Giza E, Mithöfer K, Farrell L, et al. Injuries in women's professional soccer. Br J Sports Med 2005;39:212-6. discussion 212-6.

42. Jacobson I, Tegner $Y$. Injuries among Swedish female elite football players: a prospective population study. Scand J Med Sci Sports 2007;17:84-91.

43. Soligard T, Nilstad A, Steffen K, et al. Compliance with a comprehensive warm-up programme to prevent injuries in youth football. Br J Sports Med 2010;44:787-93.

44 Van Reijen M, Vriend II, Zuidema V, et al. The implementation effectiveness of the 'Strengthen your ankle' smartphone application for the prevention of ankle sprains: design of a randomized controlled trial. BMC Musculoskelet Disord 2014;15:2474-15.

45. van Mechelen W, Hlobil H, Kemper HC, Incidence KHC. Incidence, severity, aetiology and prevention of sports injuries. A review of concepts. Sports Med 1992;14:82-99. 